\title{
Interventional closure of RPA-to-LA communication in an oligosymptomatic neonate
}

Benz, Dominik C ; Burkhardt, Barbara ; Quandt, Daniel ; Stambach, Dominik ; Knirsch, Walter ; Kretschmar, Oliver

\begin{abstract}
Direct communication between the right pulmonary artery (RPA) and the left atrium (LA) is a very rare cardiac malformation. Clinical presentation of RPA-to-LA communication depends on the size of the communication, the amount of right-to-left shunt, the patient's age, and pulmonary vascular resistance. Patients with small communications usually present oligosymptomatic and are diagnosed at an older age. A delay of diagnosis bears the risk of severe complications and needs to be prevented by proper work-up of oligosymptomatic neonates. Treatment of RPA-to-LA communications used to be performed by surgical closure, and the interventional approach has only been established as a less invasive alternative in recent years. Conclusion: Although patients with small RPA-to-LA communications usually present oligosymptomatic, early diagnosis and treatment is essential to prevent life-threatening complications.
\end{abstract}

DOI: https://doi.org/10.1007/s00431-014-2337-z

Posted at the Zurich Open Repository and Archive, University of Zurich

ZORA URL: https://doi.org/10.5167/uzh-105399

Journal Article

Published Version

Originally published at:

Benz, Dominik C; Burkhardt, Barbara; Quandt, Daniel; Stambach, Dominik; Knirsch, Walter; Kretschmar, Oliver (2014). Interventional closure of RPA-to-LA communication in an oligosymptomatic neonate. European Journal of Pediatrics, 173(12):1703-1705.

DOI: https://doi.org/10.1007/s00431-014-2337-z 


\title{
Interventional closure of RPA-to-LA communication in an oligosymptomatic neonate
}

\author{
Dominik C. Benz • Barbara Burkhardt • Daniel Quandt • \\ Dominik Stambach • Walter Knirsch • \\ Oliver Kretschmar
}

Received: 4 February 2014 / Revised: 19 April 2014 / Accepted: 7 May 2014 /Published online: 21 May 2014

(C) Springer-Verlag Berlin Heidelberg 2014

\begin{abstract}
Direct communication between the right pulmonary artery (RPA) and the left atrium (LA) is a very rare cardiac malformation. Clinical presentation of RPA-to-LA communication depends on the size of the communication, the amount of right-to-left shunt, the patient's age, and pulmonary vascular resistance. Patients with small communications usually present oligosymptomatic and are diagnosed at an older age. A delay of diagnosis bears the risk of severe complications and needs to be prevented by proper work-up of oligosymptomatic neonates. Treatment of RPA-to-LA communications used to be performed by surgical closure, and the interventional approach has only been established as a less invasive alternative in recent years. Conclusion: Although patients with small RPA-to-LA communications usually present oligosymptomatic, early diagnosis and treatment is essential to prevent life-threatening complications.
\end{abstract}

\footnotetext{
Communicated by Jaan Toelen

D. C. Benz • B. Burkhardt • D. Quandt $\cdot$ W. Knirsch $(\bowtie) \cdot$

O. Kretschmar

Division of Pediatric Cardiology, University Children's Hospital, Steinwiesstrasse, 758032 Zurich, Switzerland

e-mail: walter.knirsch@kispi.uzh.ch

D. C. Benz

e-mail: dominik.benz1@gmail.com

B. Burkhardt

e-mail: barbara.burkhardt@kispi.uzh.ch

D. Quandt

e-mail: daniel.quandt@kispi.uzh.ch

O. Kretschmar

e-mail: oliver.kretschmar@kispi.uzh.ch

D. Stambach

Division of Cardiology, Ostschweizer Kinderspital, St. Gallen, Switzerland

e-mail: dominik.stambach@kispisg.ch
}

\author{
Abbreviations \\ CHD Congenital heart disease \\ LA Left atrium \\ PDA Patent arterial duct \\ RPA Right pulmonary artery
}

\section{Introduction}

Direct communication between the right pulmonary artery (RPA) and the left atrium (LA) is a very rare cardiac malformation. A current PubMed search revealed approximately 100 cases $[3,5-7,9,11]$. The majority of these cases were congenital, only two had a traumatic aetiology [12]. Modalities for diagnosis include clinical examination, chest X-ray, colour flow Doppler echocardiography, MRI, and cardiac catheterization with selective angiography. According to Chowdhury and colleagues [4], communications between RPA and LA can be classified into four types (I, II, III, and IV) that have a consequence on the appropriate surgical approach of repair. Although surgical repair is performed with very low mortality, catheter-guided interventional closure of RPA-to-LA communications has been established as a less invasive alternative [5; 9]. Luo and colleagues [7] compared the outcome of the surgical and the interventional approach and concluded that management of patients with RPA-to-LA communication should be individualized, depending on the anatomic variations, size, and the pulmonary venous connections. Particularly, interventional closure is contraindicated if pulmonary veins are involved in the communication and aneurysm formation (Type II, III, and IV), because pulmonary venous drainage may be affected.

Clinical presentation of RPA-to-LA communication depends on the size of the communication, the amount of 
right-to-left shunt, the patient's age, and pulmonary vascular resistance [7]. Patients with large communications typically present at a young age, mostly as neonates, and suffer from severe clinical symptoms such as cyanosis, tachypnea, and respiratory distress. On the other hand, patients with small communications have milder symptoms like exertional dyspnea, a nonspecific cardiac murmur, or just a slightly decreased oxygen saturation. A delay of diagnosis bears the risk of pulmonary hypertension, endocarditis, paradoxical embolism, and progressive aneurysmal growth of the fistula.

\section{Case report}

We present an oligosymptomatic male premature infant after uneventful pregnancy and spontaneous delivery (APGAR 6/7/ 7) at a gestational age $364 / 7$ weeks and birth weight $3.620 \mathrm{~g}$ ( $>90$ percentile) showing persistent slightly reduced transcutaneous oxygen saturations (87-91\%) during the first week after birth in an otherwise good clinical condition with unremarkable physical examination. Transthoracic twodimensional colour Doppler flow echocardiography revealed
RPA-to-LA communication as a reason for the reduced oxygen saturations. Due to his excellent clinical course and ongoing physical growth, the infant was planned for later (after 6-12 months of age) interventional closure of the RPA-to-LA communication.

On elective admission, 11 months after birth, the infant was still oligosymptomatic with only a low oxygen saturation of $92 \%$. Transthoracic echocardiography revealed a communication with a fistula and aneurysmatic dilatation originating from the RPA to the LA causing a right-to-left shunt, with an otherwise normal cardiac anatomy (Fig. 1a). In the RPA angiography (Fig. 1b), the fistula measured $6 \mathrm{~mm}$ at the pulmonary end, narrowed down to $2.7 \mathrm{~mm}$, and widened again to $7.8 \mathrm{~mm}$ at its atrial end with an aneurysmatic dilatation (with a diameter of $18 \times 18 \mathrm{~mm}$ ) at the draining part into the LA (Type I according to Chowdhury [4]). The fistula was entered from the RPA and subsequently successfully closed with a detachable patent ductus arteriosus (PDA) coil $(9 \times$ $6 \mathrm{~mm}$, Nit-Occlud ${ }^{\circledR}$; PFM, Cologne, Germany). The oxygen saturation rose immediately from 92 to $100 \%$. The final angiography (Fig. 1c) showed an optimal coil position with minimal residual shunt. One day later, colour flow Doppler
Fig. 1 a Short-axis view of transthoracic echocardiography showing the fistula (arrows) with aneurysm (dotted line) between the right pulmonary artery (RPA) and the left atrium (LA). b RPA angiogram demonstrating aneurysmatic dilation of the fistula before draining into the LA. c RPA angiogram after fistula closure with the occluding coil in place. d Short-axis view of TTE showing no relevant residual shunting from RPA to LA one day after coiling (dotted line)

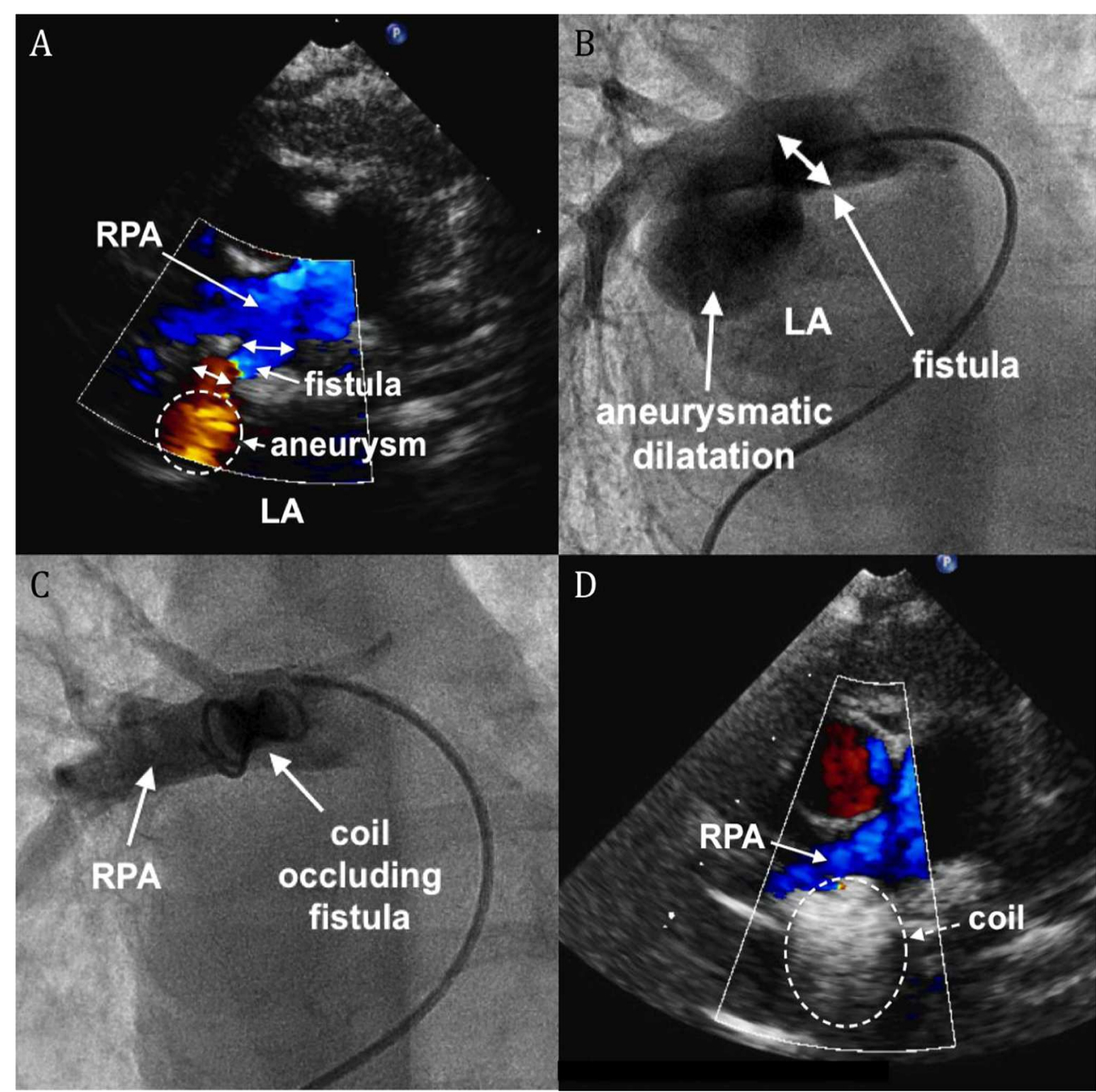


echocardiography (Fig. 1d) showed no residual right-to-left shunting and, even though the coil was slightly extended into the RPA, there was no relevant hemodynamic flow impairment in the RPA. We used the PFM coil due to its shape and properties; as an alternative, the Amplatzer Duct Occluder II could be also a suitable soft device.

After 12 months, clinical follow-up was uneventful with no signs of cyanosis. Transthoracic echocardiography showed the coil in stable position with a laminar flow pattern in the right pulmonary artery and pulmonary veins.

At our centre, we have now seen two patients with a RPAto-LA communication presenting a wide spectrum of clinical presentation. Our last case [3] presented with central cyanosis and clinical sign of respiratory distress. The patient was administered epinephrine and milrinone to stabilize her condition. The patient we relate to in this short communication was oligosymptomatic with low transcutaneous oxygen saturations only.

Therefore, diagnostic work-up of cyanosis in the term newborn includes differentiation of cardiac, respiratory, metabolic, hematologic, neurologic, and other pathologies. Screening for cardiac pathologies remains difficult due to the fact that around half (56\%) of all newborns with congenital heart disease (CHD) are asymptomatic in the first few days of life. Moreover, if a cardiac murmur can be auscultated, it is only specific in $54 \%$ of all cases for an underlying cardiac malformation [1]. When discharged from hospital, only $76 \%$ of all CHD patients were diagnosed with their disease [8]. Postductal pulse oximetry was shown to be an effective method for early detection of CHD [2]. It was performed from 6 to $12 \mathrm{~h}$ after birth in all newborns greater than 35 weeks of gestation. If transcutaneous oxygen saturation was below $95 \%$, echocardiography was performed. The recommendations by the Swiss Society of Neonatology imply immediate echocardiography below $90 \%$. If oxygen saturation was between 90 and $94 \%$, a second measurement is recommended after a couple of hours. It would be succeeded by echocardiography if oxygen saturation had not increased above $94 \%$. The same algorithm has also been recommended by the CDC (United States Centers for Disease Control and Prevention). If the cardiac malformation is not detected by conventional echocardiography, saline contrast medium can be applied to increase sensitivity for the diagnosis of a right-to-left shunt [10]. Ultimately, diagnostic work-up can be extended to MR scan or cardiac catheterization.
In conclusion, this case report shows the necessity of clinical work-up of mild forms of cyanosis in infants. Although our patient presented only with slightly reduced oxygen saturations after diagnosis, using transthoracic echocardiography treatment of the malformation was indicated avoiding long-term complications. Furthermore, our case illustrates the interventional closure of an RPA-to-LA communication (Type I) as a safe procedure with a favourable outcome.

Conflict of interest All the authors declare no conflict of interest and no financial support.

\section{References}

1. Ainsworth S, Wyllie JP, Wren C (1999) Prevalence and clinical significance of cardiac murmurs in neonates. Arch Dis Child Fetal Neonatal Ed 80:F43-F45

2. Arlettaz R, Bauschatz AS, Mönkhoff M, Essers B, Bauersfeld U (2006) The contribution of pulse oximetry to the early detection of congenital heart disease in newborns. Eur J Pediatr 165:94-98

3. Burkamp A, Ghisla R, Knirsch W, Kretschmar O, Balmer C (2012) Catheter interventional closure of a large right pulmonary artery-toleft atrial communication in a neonate. Pediatr Cardiol 33:1440-1442

4. Chowdhury UK, Kothari SS, Airan B, Subramaniam KG, Venugopal P (2005) Right pulmonary artery to left atrium communication. Ann Thorac Surg 80:365-370

5. Ece I, Uner A, Cuce F, Balli S (2014) Transcathether closure of a right pulmonary artery-to-left atrial fistula using Amplatzer muscular ventricular septal defect occluder. Cardiovasc Interv Ther. 2014 Jan 4. [Epub ahead of print]

6. Gajjar TP, Desai NB (2012) Bicameral repair of right pulmonary artery to left atrial communication. Thorac Cardiovasc Surg 60:229232

7. Luo GH, Ma WG, Huang LJ, Yan J, Zhu XD (2011) Surgical and transcatheter closure of right pulmonary artery to left atrial fistula. J Card Surg 26:130-134

8. Meberg A, Otterstad JE, Frøland G, Hals J, Sörland SJ (1999) Early clinical screening of neonates for congenital heart defects: the cases we miss. Cardiol Young 9:169-174

9. Sarkar A, Chandra GSN, Majhi B, Mandal S, Pande A, Ahmed I (2013) Rare variant of pulmonary arteriovenous fistula: direct communication between right pulmonary artery and left atrium associated with aortopulmonary collaterals. J Am Coll Cardiol 62:859

10. Van Hare GF, Silverman NH (1989) Contrast two-dimensional echocardiography in congenital heart disease: techniques, indications and clinical utility. J Am Coll Cardiol 13:673-686

11. Wang X, Mei Y, Xie S, Ji Q (2012) Direct communication between the right pulmonary artery and the left atrium: presenting with other congenital anomalies. Eur J Cardiothorac Surg 41:e127

12. Young TE, Sukhum P, Molina JE (1982) Traumatic fistula between the right pulmonary artery and the left atrium. Minn Med 65:227-229 